\section{Private Higher Education in the United Kingdom: Myths and Realities}

\section{Steve Woodfield}

Steve Woodfield is a senior researcher, Vice-Chancellor's Office, Kingston University London, UK. E-mail: s.woodfield@kingston.ac.uk.

$\mathrm{T}^{\mathrm{h}}$ he UK independent sector remains relatively small. Around $\mathrm{I} 60,000$ students were studying for UK awards in 20II-20I2 in independent institutions, compared with 2.3 million students in the publicly funded sector. Recent research identified 674 independent higher education institutions and most students are concentrated in a small number of larger providers in England (mostly in and around London). Many private higher education institutions are either new or have been recently reconfigured in response to policy changes that have encouraged expansion, and enrollments are growing rapidly.

\section{Myth No 1: Few Private Providers}

All UK higher education institutions are technically private (as defined by the Organization for Economic Cooperation and Development) although the system is dominated by universities and colleges that receive government funding. The government describes that higher education providers run privately and not in receipt of recurrent public funding for teaching and research as "alternative providers" and private institutions term themselves as "the independent sector." Higher education is a devolved policy area in the United Kingdom, and public funds are distributed by independent funding councils in the four UK countries who attach certain conditions and regulatory controls to this funding.

\section{Myth No. 2: Private Providers Are a Homogenous Group}

The UK independent sector is highly diverse in terms of mission, ownership, size, subject specialisms, student profile, fee levels, and level of awards. There are four-main groupings of independent higher education institutions: those that can award their own degrees (recognized bodies); those whose UK- and European Union-domiciled students can access government financial support (through specific course designation); those that can offer degrees in partnership with recognized bodies (listed bodies); and overseas institutions offering non-UK degrees, about whom very little is known. Independent institutions also offer vocational sub-degree programs examined by private companies (e.g., Pearson, EdExcel). The largest group is the listed bodies, most of which are small institutions (for-profit and nonprofit) that offer professionally orientated programs (e.g., business, creative arts/design, law, accountancy, or information technology).

There are no "elite" private universities in the United Kingdom, although recognized bodies are less regulated and tend to have larger enrollments (up to 5,000 students), recruit more UK students, offer a wider range of programs, and engage in basic and applied research. There are currently six independent recognized bodies, four charities (Regent's University London, the University of Buckingham, ifs University College, and Ashridge Business School), and two for-profit companies (BPP University and the University of Law). For-profit status is currently only important for taxation purposes, although mission (and associated differences in governance structures) may become an important differentiator under any new legislation.

\section{Around 160,000 students were study- ing for UK awards in 2011-2012 in inde- pendent institutions, compared with 2.3 million students in the publicly funded sector.}

Myth No. 3: The UK's Private Higher Education Sector IS IRRELEVANT

Despite its small size, the independent sector also provides niche, flexible, and demand-led provision (including postgraduate studies) to UK-domiciled students, complementing provision in the publicly funded sector and often provided at a lower cost. Around two-thirds of students in the sector are over 25 years, the same proportion study around employment, and many have family responsibilities. The independent sector also acts a vital recruitment channel for international students, many of whom remain in the United Kingdom after graduating, either working in highly skilled jobs or pursuing further studies in the publicly funded sector.

Recent policy changes in England have created optimum conditions for the independent sector to grow rapidly and thrive. Independent higher education institutions are becoming more attractive as they can gain university status, sponsor non-EU students, and as UK and EU-domiciled students studying in England on designated courses can access government tuition-fee maintenance loans-albeit a lower maximum level ( $£ 6,0 \circ 0$ per annum) than students studying in the publicly funded sector $(£ 9,000)$. Many independent providers are rapidly increasing their recruit- 
ment (which will be uncapped from 2015-20I6), intensifying the pressure on public higher education funding due to the associated increase, in take up of tuition-fee and livingcost loans and grants. This expansion will have a significant impact on publicly funded providers competing to recruit the same students as independent providers, while charging higher fees and receiving reduced government funding.

\section{Myth No. 4: Private Institutions Provide Poor-Quality EDUCATION}

A key feature is that all higher education institutions providing education leading to UK awards (in the country or overseas) are expected to follow the UK Quality Code for Higher Education. Educational oversight and quality assurance is provided via the Quality Assurance Agency (QAA), and professional programs are regulated by Professional, Statutory and Regulatory Bodies. A 2013 research study reported that 82 percent of students studying in the independent sector were satisfied with their provider, a figure comparable with a national survey of students in the publicly funded sector.

This higher education regulatory system protects quality through tight control over the award of "university title" and degree-awarding powers, the ability to offer degrees in collaboration with recognized bodies with degree-awarding powers, and any unplanned expansion in student recruitment. Independent institutions also undergo a rigorous course designation process covering quality assurance, financial sustainability and management, and governance arrangements.

Unlike publicly funded providers, independent ones are not currently required to offer complete data for accountability purposes, measure student satisfaction (via the National Student Survey), or provide information about their institution to support student decision making (the Key Information Set). However, as the regulatory system evolves, independent providers' accountability burden is likely to increase.

A small part of private provision operates "below the radar" offering non-UK qualifications or unaccredited provision. Some private colleges are also "diploma mills" offering fraudulent qualifications or recruiting bogus students, although the tightening of visa regulations is gradually closing down such a provision.

Myth No. 5: The Private and Public Sectors are Separate The independent sector does have a set of unique characteristics-mainly due to its uneven engagement with the United Kingdom's current regulatory, funding, and qualityassurance landscape. However, in policy terms, status differences between these institutions and more traditional providers are being eroded—as the regulatory and qualityassurance landscape slowly adapts to include them. The
English government is seeking to create a "level playing field" for all providers and to foster fairer competition.

The publication of the 20II white paper Students at the Heart of the System signaled the English government's intention to open up the sector to "alternative providers." This policy move forms part of the wider privatization and marketization of English higher education that centers around increasing access to that system-while reducing public funding, focusing on the "employability" benefits, increasing education exports, improving efficiency, and commercializing educational activities. However, the other devolved governments in the United Kingdom do not share this policy direction and the independent sectors in these countries remain both separate and small.

\section{Unlike publicly funded providers, inde- pendent ones are not currently required to offer complete data for accountability purposes, measure student satisfaction (via the National Student Survey), or provide information about their institu- tion to support student decision mak- ing.}

The publicly funded higher education also engages in various types of partnership with independent-listed bodies, via franchising and other types of collaborative provision. About 30 publicly funded institutions also partner with private-sector educational organizations-based on the delivery of pathway UK programs designed to prepare international students for entry into degree-level studies in the publicly funded sector.

Private businesses are also heavily engaged in higher education provision beyond direct program delivery, as the system becomes more and more "unbundled"-for example, by providing curriculum materials, learner support, and the technological infrastructure to support online learning (e.g., the arrangement between the University of Liverpool and Laureate Education). Publicly funded providers also increasingly outsource key-support services (e.g., information technology) and engage in shared services arrangements with private organizations. As this privatization and commercialization intensifies and the policy changes in England take effect, the boundaries between different types of higher education institutions are likely to blur, with only institutional mission (for-profit or nonprofit) being a key differentiator between the different parts of the sector. 